\title{
Stress pada Mahasiswa Keperawatan dan Strategi Koping yang Digunakan
}

\author{
Yuni Aris ${ }^{a}$, Rika Sarfika ${ }^{b}$, Ira Erwina ${ }^{b}$ \\ a Mahasiswa Program Studi Ilmu Keperawatan Universitas Andalas, Kampus Limau \\ Manis, Padang, 25163, Indonesia \\ ${ }^{\mathrm{b}}$ Bagian Keperawatan Jiwa-Komunitas Program Studi Ilmu Keperawatan Universitas \\ Andalas, Padang, 25163, Indonesia \\ e-mail korespondensi : rika.sarfika@nrs.unand.ac.id
}

\begin{abstract}
The background: students in the first year lecture is the subject of that are vulnerable are subjected to stress. Response the stress not adequat and occurring in a long period of time can cause depression and even could lead to the action of suicide. Coping positive will lead to adaptation good. The purpose of this research is to find relations between the level of stress with strategy coping. Methods: sample in this research is a student nursing faculty nursing unand the first level and the level of class two english-language internasioanl (KBI), class a regular program are fulfilled, and the class regular program incongruous as much as a 122 people. Data collected with guide interview by using a questionnaire Perceived Stress Scale-14 (PSS-14) and questionnaires adolescent coping orientation for the problem of experiences ( acope). Measurements conducted simultaneously on student each class .In an analysis of data by using chi-square analysis. Results: the research results show as many as $63.7 \%$ respectively students that experienced stress was on strategy coping that focuses on emotion, the rest of 36,3\% his use strategy coping focuses on the problem. Test results chi-square show there is meaningful relations between stress with strategy coping $(P v=$ 0,011 ). Conclusions: it is suggested that students capable of adapting to stresor by means of mensubstitusikannya into a challenges positive so the university students can remain productive without having to down to stress experienced.
\end{abstract}

Keyword : stress, coping strategy, problems, emotion, students nursing

\begin{abstract}
Abstrak
Latar Belakang: Mahasiswa pada tahun pertama perkuliahan merupakan subjek yang rentan mengalami stres. Respon stres yang tidak adequat dan terjadi dalam jangka waktu yang lama dapat menyebabkan depresi dan bahkan dapat mengarah kepada tindakan bunuh diri. Koping yang positif akan mengarahkan kepada adaptasi yang baik. Tujuan penelitian ini adalah untuk mengetahui hubungan antara stres dengan strategi koping. Metode: Penelitian ini adalah penelitian deksriptif analitik dengan pendekatan Cross-sectional. Sampel dalam penelitian ini adalah mahasiswa keperawatan Fakultas Keperawatan Unand tingkat pertama dan tingkat dua dari Kelas Berbahasa Internasioanl (KBI), kelas reguler program A genap, dan kelas reguler program A ganjil sebanyak 122 orang. Data dikumpulkan dengan teknik wawancara terpimpin dengan menggunakan kuesioner Perceived Stress Scale-14 (PSS-14) dan kuesioner Adolescent Coping Orientation for Problem Experiences (ACOPE). Pengukuran dilakukan secara serentak pada mahasiswa masing-masing kelas. Data di analisis dengan menggunakan chi-square analysis. Hasil: Hasil penelitian menunjukkan sebanyak 63,7\% mahasiswa yang
\end{abstract}


mengalami stress tingkat sedang menggunakan strategi koping yang berfokus pada emosi, sedangkan sebanyak 36,3\% nya menggunakan strategi koping berfokus pada masalah. Hasil uji chi-square menunjukkan ada hubungan yang bermakna antara stres dengan strategi koping $(\mathrm{P} v=0,011)$. Kesimpulan: Disarankan agar mahasiswa mampu beradaptasi terhadap stresor dengan cara mensubstitusikannya menjadi sebuah tantangan yang positif sehingga mahasiswa bisa tetap produktif tanpa harus terpuruk dengan stres yang dialami.

Kata Kunci : Stres, strategi koping, masalah, emosi, mahasiswa keperawatan

\section{LATAR BELAKANG}

Gangguan mental saat ini masih menjadi masalah yang cukup menjadi perhatian bagi pemerintah Indonesia khususnya Provinsi Sumatera Barat. Data Riset Kesehatan Dasar (Riskesdas) tahun 2013 mengungkapkan bahwa prevalensi nasional gangguan mental emosional seperti stress dan depresi pada penduduk umur 15 tahun ke atas sebesar $6 \%$, di Sumatera Barat angka ini lebih rendah yaitu sebesar 4,5\%. Namun, prevalensi gangguan mental berat di Provinsi Sumatera Barat lebih tinggi sebesar $0,2 \%$ dibanding prevalensi nasional. Tinggi nya angka gangguan mental berat di Sumatera Barat dapat menimbulkan beban bagi Pemerintah Daerah tersebut. Beban ini akan menjadi lebih berat jika gangguan mental emosional seperti stress dan depresi tidak ditangani dengan serius.

Stres merupakan sebuah interaksi antara individu dengan lingkungannya yang menyebabkan munculnya ketegangan dan tantangan bagi individu itu sendiri untuk mengatasinya (Fortinash \& Worret, 2012). Mahasiswa pada tahun pertama kuliah khususnya mahasiswa keperawatan merupakan subjek yang rentan mengalami stres seperti tekanan terhadap proses akademik, keraguan terhadap masa depan, dan kesulitan beradaptasi dengan lingkungan baru di Kampus (Chorousos, et al, 1998; dalam Kumar \& Nancy, 2011).

Beberapa penelitian menunjukkan mahasiswa keperawatan rentan mengalami stres. Penelitian Kumar dan Nancy pada tahun 2011 terhadap 180 mahasiswa keperawatan di Private Nursing Institute of Punjab dan Baba Farid University of Health Sciences New Delhi, didapatkan gambaran bahwa sebanyak 62 orang mahasiswa (34,4\%) mengalami stres tingkat sedang, 59 orang mahasiswa $(32,8 \%)$ mengalami stres ringan dan berat. Kemudian penelitian Singh dan Kohli pada tahun 2015 terhadap 139 mahasiswa keperawatan di kota New Delhi dan didapatkan hasil bahwa 107 orang (76,9\%) mahasiswa mengalami stres sedang, 27 orang $(19,4 \%)$ lainnya mengalami stres ringan dan 5 orang $(3,6 \%)$ mengalami stres berat. Kedua hasil penelitian ini menunjukkan bahwa kondisi stress pada 
NERS: Jurnal Keperawatan, Volume 14, No. 2, Oktober 2018, (Hal. 81-91)

mahasiswa keperawatan

memperihatinkan.

Stres dikalangan mahasiswa bisa berdampak kepada nilai akademik yang buruk, depresi dan bahkan bisa melakukan tindakan bunuh diri (Pheukphan, 2009). Peristiwa bunuh diri merupakan fenomena yang kerap menjadi perhatian pemerintah. World Health Organization (WHO) pada tahun 2010 melaporkan angka bunuh diri di Indonesia mencapai 1,6 hingga 1,8 per 100.000 jiwa.

Stres pada setiap orang akan menimbulkan respon yang berbeda-beda. Respon stres yang berbeda akan melahirkan strategi koping yang berbeda-beda pula tergantung kepada jenis koping yang digunakan. Koping itu sendiri bersifat disengaja, terencana dan merupakan usaha secara psikologis untuk mengelola dampak dari stres. Koping yang positif akan mengarah kepada adaptasi yang baik dengan karakteristik yang seimbang antara sehat dan sakit, sebagai bentuk perwujudan dari jiwa yang sejahtera dan fungsi sosial yang bagus.

Stres yang tidak terkelola dengan baik dapat menimbulkan perasaan kesepian, kegelisahan, tidak bisa tidur dan kekhawatiran yang berlebihan. Munculnya berbagai stresor memberikan tantangan terhadap kemampuan koping mahasiswa. Kegagalan dalam mengembangkan strategi koping yang berespon terhadap setiap stresor yang muncul lebih sering Yuni Aris, dkk., Stress pada Mahasiswa Keperawatan,... 
METODE

Penelitian ini merupakan penelitian deskriptif dengan pendekatan cross sectional. Penelitian ini dilakukan di Fakultas Keperawatan Universitas Andalas Padang Provinsi Sumatera Barat. Sampel dalam penelitian ini adalah mahasiswa keperawatan program A (reguler) tingkat satu dan tingkat dua. Besar sampel sebanyak 122 orang yang diambil secara total sampling.

Alat ukur yang digunakan adalah kuesioner Perceived Stress Scale-14 (PSS14) untuk mengukur tingkat stress pada mahasiswa keperawatan dan kuesioner Adolescent Coping Orientation for Problem Experiences (ACOPE) untuk melihat strategi koping yang digunakan mahasiswa keperawatan dalam mengatasi stress yang dialaminya. Data di analisis dengan menggunakan uji chi-square.

\section{HASIL}

3.1. Gambaran Stres dan Strategi Koping Responden

Tabel 1. Distribusi Tingkat Stres Responden

\begin{tabular}{lrr}
\hline Variabel & \multicolumn{1}{l}{$\%$} \\
\hline Tingkat stres: & & \\
Stres ringan & 20 & 16.4 \\
Stres sedang & 102 & 83.6 \\
Total & 122 & 100 \\
\hline Strategi koping: & & \\
Berfokus pada masalah & 51 & 41.8 \\
Berfokus pada emosi & 71 & 58.2 \\
Total & 122 & 100 \\
\hline
\end{tabular}

Tabel 1. Menunjukkan bahwa sebagian besar responden berada pada stres tingkat sedang $(83,6 \%)$ dan lebih dari separuh responden memiliki strategi koping yang berfokus pada emosi $(58,2 \%)$.

\subsection{Hubungan Stres Dengan Strategi Koping}

Tabel 2.Analisis Hubungan Stres Dengan Strategi Koping $(n=122)$

\begin{tabular}{llrrrrrr}
\hline \multirow{2}{*}{$\begin{array}{c}\text { Tingkat } \\
\text { Stres }\end{array}$} & \multicolumn{5}{c}{ Strategi Koping } & \multirow{2}{*}{$P$} \\
\cline { 2 - 6 } & $\begin{array}{l}\text { Berfokus } \\
\text { masalah }\end{array}$ & \multicolumn{2}{c}{$\begin{array}{c}\text { Berfokus } \\
\text { emosi }\end{array}$} & \multicolumn{2}{c}{ Total } & \\
& \multicolumn{1}{c}{$f$} & $\%$ & $f$ & $\%$ & $f$ & $\%$ & \\
\hline Ringan & 14 & 70 & 6 & 30 & 20 & 100 & 0.01 \\
Sedang & 37 & 36.3 & 65 & 63.7 & 102 & 100 & \\
Total & 51 & 41.8 & 71 & 58.2 & 122 & 100 & \\
\hline & & & & & & &
\end{tabular}

Tabel 2. Menunjukkan bahwa dari 102 responden yang mengalami stres tingkat sedang, lebih dari separuhnya $(63,7 \%)$ menggunakan strategi koping yang berfokus pada emosi, sedangkan sebanyak $36,3 \%$ menggunakan strategi koping yang berfokus pada masalah. Sementara dari 20 responden yang mengalami stres ringan, lebih dari separuh menggunakan strategi koping yang berfokus pada masalah (70\%), dan sebanyak 30\% menggunaka strategi koping yang berfokus pada emosi.

Tabel 2. Juga menunjukkan nilai $\mathrm{P} v=0,011 \quad(\alpha<0,05)$. Artinya ada hubungan yang bermakna antara stres dengan strategi koping pada mahasiswa keperawatan 
program A (reguler) Fakultas Keperawatan Universitas Andalas.

\section{PEMBAHASAN}

\section{Stres}

Hasil penelitian ini menemukan bahwa sebagian besar mahasiswa keperawatan mengalami stres tingkat sedang $(83,6 \%)$, sebagian kecil mengalami stres tingkat ringan $(16,4 \%)$. Penelitian ini hampir sama dengan penelitian Singh \& Kohli pada tahun 2015 yaitu dari 139 mahasiswa keperawatan di kota New Delhi ditemukan sebagian besar mahasiswa berada pada stres sedang $(76,9 \%)$ dan sebagian kecil berada pada stress ringan $(19,42 \%)$. Penelitian ini menunjukkan bahwa mahasiswa keperawatan rentan mengalami stres pada tahun pertama perkuliahan mereka.

Setiap fase kehidupan tidak akan pernah terlepas dari stres. Ketika seseorang sedang menjalani perkuliahan di Sekolah Tinggi Keperawatan, maka mahasiswa akan menghadapi berbagai macam materi pelajaran baru yang mengharuskan mereka mampu menganalisis informasi yang didapat dan mengaplikasikannya di berbagai kondisi termasuk di Kelas, Laboratorium, dan Klinik. Mahasiswa merasa terus dihadapkan pada tantangan di kampus dan sering merasa tertekan.

Mahasiswa yang mengalami stres sedang mengalami tanda dan gejala seperti perasaan tidak mampu mengatasi masalah sederhana yang seharusnya bisa diselesaikan sendiri, menjadi mudah marah, merasa bahwa kesulitan yang dialami adalah hal yang sulit di atasi sehingga mereka lebih cenderung untuk pasrah terhadap keadaan, merasa gugup dan tertekan terhadap masalah yang dihadapi.

Salah satu faktor yang menyebabkan mahasiswa berada pada tingkat stres sedang adalah faktor usia. Pada penelitian ini mahasiswa keperawatan program A tahun 2014 dan 2015 memiliki rentang usia antara 17-20 tahun, menurut WHO rentang usia ini adalah fase remaja akhir.

Remaja akhir biasanya memiliki energi yang besar, emosi yang masih berkobar-kobar, sedangkan pengendalian diri belum sempurna. Remaja akhir juga sering mengalami perasaan tidak aman, tidak tenang dan kesepian (Isra \& Asrori, 2010). Periode remaja sering disebut sebagai “ badai dan tekanan," suatu kondisi dimana emosi meninggi. Tingginya emosi disebabkan oleh adanya tekanan sosial dari lingkungannya dan ketakutan menghadapi kondisi yang baru (Hurlock, 2012). Dengan demikian, usia yang masih muda menjadi faktor pemicu meningkatnya stres dikalangan mahasiswa.

Selain faktor usia, stres juga dapat dikaitkan dengan jenis kelamin. Respon stres pada laki-laki lebih cendrung menimbulkan keadaan patologis pada fungsi 
fisik dan mental. Pada perempuan lebih sering melakukan mekanisme pertahanan stres melalui dukungan sosial dari perempuan lain untuk memberi dan menerima dukungan sosial. Pola respon ini dikenal dengan sebutan "tend and befriend," sedangkan laki-laki jarang melakukan mekanisme pertahanan seperti ini.Pola ini berfungsi sebagai katarsis yang bisa menurunkan tingkat ancaman, mengurangi respon simpatis, dan mengurangi aktivitas locus cerelus dan aksis hipotalamushipofisis-adrenal. Hal ini memberikan bukti bahwa fungsi mental dan substrat biologis perempuan lebih unggul dibandingkan dengan laki-laki (Hurlock, 2012).

Faktor lain yang mempengaruhi stres pada mahasiswa adalah tinggal jauh dari keluarga. Pada penelitian ini didapatkan hasil bahwa sebagian besar mahasiswa tinggal di tempat kost $(80,3 \%)$ dan sebagian kecil tinggal di rumah sendiri/tinggal bersama orang tua $(19,7 \%)$. Ali \& Asrori (2010) menjelaskan bahwa banyak hal dari dalam keluarga yang dibutuhkan oleh mahasiswa dalam proses perkembangan sosialnya, yaitu kebutuhan akan rasa aman, dihargai, disayangi, diterima, dan kebebasan untuk menyatakan diri. Rasa aman meliputi perasaan aman secara material dan mental. Kondisi yang aman secara material seperti pemenuhan kebutuhan terhadap pakaian, makanan, dan sarana lain yang diperlukan sejauh tidak berlebihan dan tidak berada Yuni Aris, dkk., Stress pada Mahasiswa Keperawatan,... diluar kemampuan orang tua. Perasaan aman secara mental meliputi pemenuhan oleh keluarga dalam bentuk perlindungan emosional, menjauhkan ketegangan, membantu dalam menyelesaikan ketegangan dalam menyelesaikan masalah yang sedang di hadapi, dan memberikan bantuan dalam menstabilkan emosinya.

Stres pada mahasiswa bertambah berat ketika permasalahan seperti tugastugas perkuliahan yang tidak bisa diselesaikan tepat waktu dan nilai ujian yang tidak sesuai dengan harapan. Hal ini sesuai dengan hasil penelitian yang menunjukkan bahwa sebanyak $72,5 \%$ mahasiswa mengatakan bahwa yang membuat mereka sering merasakan stres adalah karena sering memikirkan tugas-tugas perkuliahan yang banyak dan harus diselesaikan dalam waktu yang singkat. Oleh sebab itu, perhatian dan pengawasan khususnya orang tua, dukungan teman sebaya dan juga dosen sangat dibutuhkan sehingga mahasiswa mampu untuk mengelola stres yang bersifat destruktif (distres) menjadi sebuah challenge yang positif.

\section{Strategi Koping}

Dari hasil penelitian diketahui bahwa lebih dari separuh mahasiswa $(58,2 \%)$ memiliki strategi koping yang berfokus pada emosi dan hampir separuh mahasiswa $(41,8 \%)$ memiliki strategi koping yang 
berfokus pada masalah. Bentuk strategi koping yang paling sering digunakan oleh mahasiswa keperawatan adalah memperpanjang jam tidur $(76,6 \%)$

Strategi koping adalah sesuatu yang disengaja, direncanakan dan merupakan upaya psikologis dalam mengelola pengaruh dari ketegangan yang muncul. Koping yang positif mengarah kepada adaptasi yang dikarakteristikkan oleh adanya keseimbangan antara kesehatan dan kesakitan, kesejahteraaan, dan fungsi yang optimal. Ketika seseorang tidak memiliki koping yang baik, maka yang muncul adalah tindakan maladaptif yang bisa merubah keseimbangan ke arah yang lebih buruk, kurangnya konsep diri dan kemunduran dalam menjalankan fungsi social (boyd, 2012).

Kedua strategi koping ini tidak ada salah satu yang terbaik untuk semua kondisi. Kedua strategi tersebut akan terjadi secara otomatis dan akan berkembang menjadi pola tertentu pada setiap orang. Hal yang diharapkan adalah apapun strategi koping yang dipakai bisa bekerja dengan efektif (Lazarus, 2001; Boyd, 2012).

Jenis strategi koping yang digunakan oleh setiap orang akan berbeda-beda tergantung kepada jenis stresor, respon terhadap stres, dan tingkat stres serta aksi bawaan. Selain faktor tersebut peneliti berasumsi bahwa usia dan jenis kelamin juga akan mempengaruhi jenis strategi koping yang digunakan dalam berespon terhadap stres. Usia remaja dan dewasa memiliki karakteristik yang berbeda-beda sesuai dengan tugas perkembangannya (Fortinash \& Worret, 2012).

Selain itu, emosi juga memainkan peranan penting dalam pola berfikir maupun bertingkah laku pada individu. Beberapa ciri utama pikiran emosional tersebut antara lain adalah respon yang cepat dan ceroboh. Hal ini ditandai dengan pikiran emosional yang ternyata jauh lebih cepat daripada pikiran rasional karena pikiran emosional langsung bertindak tanpa mempertimbangkan apapun yang dilakukannya. Beberapa ciri yang lain diantaranya adalah lebih mendahulukan perasaan dibandingkan pikiran, memperlakukan realitas sebagai realitas simbolik, masa lampau diposisikan sebagai masa sekarang, dan realitas yang ditentukan oleh keadaan (Goleman 1995; Ali \& Asrori 2010). Dengan demikian, kondisi ini dapat mempengaruhi mahasiswa menggunakan strategi koping yang berfokus pada emosi.

Faktor lain yang mempengaruhi strategi koping adalah perbedaan jenis kelamin. Pria dan wanita memiliki strategi koping yang berbeda-beda (Friedman, 2014). Hasil penelitian yang dilakukan oleh Burr (1994; Friedman, 2014) menjelaskan bahwa dari 180 strategi koping yang diteliti pria dan wanita memiliki perbedaan yang sangat signifikan dalam menggunakan sepuluh strategi koping. Wanita 
menganggap lebih bermanfaat berkumpul bersama orang lain, berbagi kekhawatiran atau kesulitan mereka dengan teman dan kerabat, mengungkapkan perasaan dan emosi yang positif dan negatif secara terbuka, dan menghabiskan waktu untuk mengembangkan diri dan hobi. Disisi lain, pria cenderung menggunakan strategi yang lebih menarik diri seperti dengan cara mencoba menyimpan perasaannya dan mengonsumsi alkohol lebih banyak.

\section{Hubungan Tingkat Stres dengan Strategi Koping}

Dari hasil penelitian dapat diketahui bahwa dari 102 mahasiswa yang mengalami stres tingkat sedang, lebih dari separuhnya memiliki strategi koping yang berfokus pada emosi $(63,7 \%)$ dan sebagian kecil memiliki strategi koping yang berfokus pada masalah (36,3\%) dan dari 20 mahasiswa yang mengalami stres ringan, sebagian besar memiliki strategi koping yang berfokus pada masalah (70\%) dan sebagian kecil memiliki strategi koping yang berfokus pada emosi (30\%).

Hasil uji chi-square diperoleh nilai $\mathrm{P} v=0,011(\alpha<0.05)$. Artinya, ada hubungan yang bermakna antara stres dengan strategi koping pada mahasiswa keperawatan program A (reguler) Fakultas Keperawatan Universitas Andalas.

Respon stres setiap individu berbedabeda. Respon stres yang berbeda akan Yuni Aris, dkk., Stress pada Mahasiswa Keperawatan,... melahirkan strategi koping yang berbedabeda pula tergantung kepada jenis koping yang digunakan (Boyd, 2012).

Menurut analisa peneliti, Strategi koping yang digunakan mahasiswa tidak selalu ditentukan oleh tingkat stres itu sendiri. Orang yang mengalami stres ringan tidak selalu menggunakan strategi koping yang berfokus pada masalah dan begitu juga sebaliknya orang yang mengalami stres berat juga tidak selalu menggunakan strategi koping yang berfokus pada emosi bahkan mungkin bisa menggunakan kombinasi diantara keduanya.

Namun hal yang perlu diwaspadai adalah apabila stresor yang muncul tidak mampu diatasi dengan strategi koping yang baik, akibatnya akan bisa berlanjut kepada stres pada tingkatan yang lebih berat atau bahkan sampai kepada depresi berat yang berakibat pada tindakan yang merusak diri seperti bunuh diri. Hal ini sesuai dengan hasil penelitian Peukpehan (2009), bahwa stres berat akan memberikan dampak yang sangat signifikan yang terlihat dalam bentuk gejala-gejala seperti depresi dan bahkan kemungkinan untuk melakukan tindakan bunuh diri dikalangan mahasiswa keperawatan.

Selain itu, hal yang perlu dipertimbangkan dalam menggunakan strategi koping yang sesuai dan efektif adalah adanya dukungan sosial seperti dukungan dari teman dan orang tua 
sehingga strategi koping yang digunakan bisa efektif dan efisien. Dari hasil penelitian dapat diketahui bahwa dari semua mahasiswa yang berada pada stres tingkat ringan (20 orang), lebih dari separuh berada pada kategori sering dan hampir selalu meminta dukungan teman $(60 \%)$ dan sebagian besar sering dan hampir selalu meminta dukungan keluarga apabila menghadapi masalah (75\%). Hal ini sesuai dengan apa yang dikemukakan oleh Boyd (2012), bahwa dukungan sosial menjadi sesuatu yang sangat penting dalam membantu orang untuk mengatasi stres. Strategi koping yang sukses dalam mengatasi stres adalah apabila berefek pada peningkatan kualitas hidup, kesehatan fisik dan mental.

Pada penelitian ini sebagian besar mahasiswa yang mengalami stres tingkat sedang $(83,6 \%)$, lebih dari separuh memiliki strategi koping yang berfokus pada emosi $(63,7 \%)$. Peneliti berpendapat bahwa hal ini terjadi karena subjek penelitiannya adalah mahasiswa yang berada pada masa remaja akhir. Hurlock, (2012) mengemukakan bahwa masa remaja merupakan masa yang penuh dengan emosi yang meluap-luap dan tidak terkendali. Beberapa hal yang menyebabkan tingginya emosi pada remaja adalah tekanan sosial dari lingkungannya dan ketakutan menghadapi kondisi yang baru. Hal-hal diatas menjadi faktor pemicu meningkatnya stres dikalangan mahasiswa.
Stres yang tinggi memberikan pengaruh yang besar terhadap pola berfikir dan bertingkah laku pada mahasiswa. Pola pikir yang emosional lebih dominan dibandingkan dengan pikiran rasional sehingga dalam menghadapi berbagai stresor yang ada lebih mendahulukan perasaan dibandingkan pikiran.

Ali dan Asrori

mengungkapkan bahwa pikiran emosional pada remaja cenderung cepat dan ceroboh. Hal ini ditandai dengan pikiran emosional yang ternyata jauh lebih cepat daripada pikiran rasional karena pikiran emosional langsung bertindak tanpa mempertimbangkan apapun yang dilakukannya. Hal inilah yang menyebabkan strategi koping yang dimiliki mahasiswa lebih cenderung berfokus pada emosi dibandingkan dengan strategi koping yang berfokus pada masalah.

\section{KESIMPULAN DAN SARAN}

Hasil penelitian menunjukkan adanya hubungan antara stres dengan strategi koping. Sebagian besar mahasiswa yang mengalami stres sedang lebih cenderung menggunakan strategi koping yang berfokus pada emosi, sedangkan pada mahasiswa yang mengalami stres ringan lebih cenderung menggunakan strategi koping yang berfokus pada emosi. 
Berdasarkan pada hasil penelitian maka disarankan kepada mahasiswa agar mampu beradaptasi terhadap stresor dengan cara mensubstitusikannya menjadi sebuah tantangan yang positif sehingga mahasiswa tetap mampu melakukan aktifitas tanpa harus tertekan karena stres yang dialami. Disamping itu, diharapkan Fakultas Keperawatan Universitas Andalas menyediakan fasilitas ruangan khusus untuk konseling bagi mahasiswa dan optimalisasi fungsi Pembimbing Akademik (PA) sehingga dapat membantu mahasiswa mencari pemecahan masalah yang dihadapinya.

Untuk melengkapi penelitian ini maka peneliti merekomendasikan penelitian lanjutan yang menggali secara detail tentang hal-hal apa saja yang menyebabkan stress pada mahasiswa serta intervensi yang tepat untuk mengatasi stres agar tidak berlanjut pada depresi.

\section{UCAPAN TERIMA KASIH}

Penelitian ini merupakan penelitian mandiri peneliti bersama mahasiswa. Dimana sejak tahun 2015, peneliti fokus melakukan penelitian dan pengabdian masyarakat pada individu kelompok sehat dan resiko gangguan jiwa.

\section{DAFTAR PUSTAKA}

Akbar, R. (2015). Mahasiswa Unand yang tewas di pintu Musala murni bunuh diri. Diakses pada tanggal 23 November 2015 dari

http://daerah.sindonews.com/read/999407 /174/mahasiswa-unand-yang-tewas-dipintu-musala-murni-bunuh-diri1431226772.

Ali \& Asrori. (2010). Psikologi remaja. Jakarta: PT Bumi Aksara.

Boyd, Ann. (2012). Psychiatric nursing contemporary practice. USA: Aptara, Inc.

Dharma, KK. (2011). Metodologi penelitian keperawatan. Jakarta: Trans Info Media.

Fortinash \& Holoday W. (2012). Psychiayric mental health nursing. USA: Mosby, Inc., an affiliate of Elseiver Inc.

Firedman, Bowden \& Jones. (2014). Keperawatan keluarga. Jakarta: EGC.

Glanz, Rimer \& Viswanath. (2008). Health behavior and health education. San Fransisco: Jossey-Bass.

Hogan, Maryann. (2013). Mental health nursing reviews \& rationals. USA: GEX Publising Services.

Hurlock, B. (2012). Psikologi perkembangan. Jakarta: Erlangga.

Katsarou, A. et al. (2012). Validation of a Greek Version of PSS-14; a Global Measure of Perceived Stress. Cent Eur Journal Public Health 2012;20 (2):104109

Kluwer, W. et al. (2011). Psychiatric-mental health nursing: fifth edition. Philadelpia: MPS Limited, A Macmillan Company.

Kumar, R \& Nancy. (2011).Stress and Coping Strategies among Nursing Students. Nursing and Midwifery Research Journal, Vol-7, No. 4, October 2011.

Misra R, McKean M. College Student's Academic Stress and Its Relation to Their Anxiety, Time Management and Leisure Satisfaction. American Journal of Health Studies, 16(1):2001:41-51.

Mosack, Victoria. (2011). Psychiatric nursing certification review guide for the 
generalist and advanced practice psychiatric and mental health nurse. USA: Jones and Bartlett Publishers, LCC.

Nasir A, \& Muhith, A. (2011). Dasar-dasar keperawatan jiwa. Salemba Medika: Jakarta.

Nurdin E. (2012). Tumbuh kembang perilaku manusia. Jakarta: IKAPI.

Ogden, Jane. (2004). Health psychology. USA: Open University Press.

Patel, Sudha,. C. \& Jakopac, Kim., A. (2012). Manual of psychiatric nursing skill. USA: Jones \& Bartlett Learning, LCC.

Pheukphan AP. Stress and Coping Strategies Among Australian Nursing Student. (2009). diakses pada tanggal 24 November 2015 dari http://www.nurse.au.edu/.

Ruqoyah, S. (2015). Mahasiswa UI bunuh diri karena terlalu cedas. Diakses pada tanggal 22 November 2015 dari http://metro.news.viva.co.id/news/read/6 08796-psikolog--mahasiswa-ui-bunuhdiri-karena-terlalu-cerdas.

Safaria, T \& Saputra, N, E. (2012). Manajemen emosi. Jakarta: PT Bumi Aksara.

Sarwono, W. (2012). Psikologi remaja. Jakarta: Rajawali Pers.

Scheid \& Brown. (2010). A Hand book for the study of mental health. United Kingdom: Cambridge University Press.

Seyedfatemi N. Experienced stressors and coping among iranian nursing students, BMC Nursing.(2007), 6(1) diakses pada tanggal 25 November 2015 dari http://www.biomedcentral.com/14726955/6/11.

Sing, N \& Kohli, C. (2015).Stress Reaction and Coping Strategies among Nursing Student. Asian Journal Nur. Edu. And Research 5(2): April-June 2015; page 274-278.

Stuart, Gail Wiscarz. (2013). Principles and practice of psychiatric nursing. United Kingdom: Mosby, an Imprint of Elseiver Inc.
Varcarolis, M. V, \& Halter, J. M. (2010). Foundations of psychiatric mental health nursing. USA: Saunders, an imprint of Elseiver Inc.

Videbeck, Sheila. L. (2011). Psychiatricmental health nursing. USA: MPS Limited, A Macmillan Company. 